\title{
Estimation of Clearance and Bioavailability of Therapeutic Monoclonal Antibodies from Only Subcutaneous Injection Data in Humans Based on Comprehensive Analysis of Clinical Data
}

\author{
Kenta Haraya ${ }^{1}$ (D) . Tatsuhiko Tachibana ${ }^{1}$
}

Accepted: 8 April 2021 / Published online: 6 May 2021

(c) The Author(s) 2021

\begin{abstract}
Introduction Theoretically, the separate estimation of clearance (CL) and bioavailability (F) requires both intravenous and extravascular injection data. This study investigated whether $\mathrm{CL}$ and subcutaneous $\mathrm{F}$ of therapeutic monoclonal antibodies (mAbs) in humans can be separately estimated from subcutaneous injection data only.

Methods First, the geometric mean of linear pharmacokinetic parameters (CL, intercompartmental CL [Q], volume of distribution in the central compartment $\left[V_{\mathrm{c}}\right]$, and volume of distribution in the peripheral compartment $\left.\left[V_{\mathrm{p}}\right]\right)$ after intravenous injection for mAbs in humans that have been reported in public data sources was estimated from $103 \mathrm{mAbs}$ with linear pharmacokinetics and $44 \mathrm{mAbs}$ with nonlinear pharmacokinetics. Next, we estimated the CL and $F$ of $25 \mathrm{mAbs}$ with linear pharmacokinetics from plasma/serum mAb concentration-time profiles after subcutaneous injection in humans by fixing the geometric mean of $Q, V_{\mathrm{c}}$, and $V_{\mathrm{p}}$ based on the public data. Moreover, the plasma/serum concentration-time profile of 25 mAbs after intravenous injection was simulated using the estimated CL and the geometric mean of $Q, V_{\mathrm{c}}$, and $V_{\mathrm{p}}$.

Results There were no significant differences in parameters among subclasses (immunoglobulin [Ig] G1, 2, and 4) or in linearity (derivation from linear and nonlinear pharmacokinetics). Using only subcutaneous injection data, we successfully estimated the CL of 23/25 mAbs (92\%) and F of all $25 \mathrm{mAbs}(100 \%)$ within 1.5-fold of the observed value. Moreover, overall, the simulated concentration-time profiles were largely consistent with observed data $(90.8 \%$ within 1.5 -fold of the observed values).

Conclusions This approach does not require intravenous injection data to separately estimate CL and F after subcutaneous injection in humans and can therefore accelerate the clinical development of mAbs.
\end{abstract}

\section{Introduction}

Therapeutic monoclonal antibodies (mAbs) have dramatically changed the treatment of numerous diseases, including cancers, autoimmune diseases, and infections [1,2]. Since mAbs have large molecular weight, oral formulations are ineffective and they must therefore be injected intravenously, subcutaneously, or intramuscularly [3]. Recently, subcutaneous injection has become more common in clinics because of its convenience [4].

In subcutaneous injection, bioavailability $(F)$ is important for determining the absorption properties of drugs and the required dosage. $\mathrm{F}$ is estimated from the ratio of area

Kenta Haraya

haraya.kenta@chugai-pharm.co.jp

1 Chugai Pharmaceutical Co., Ltd, 1-135 Komakado, Gotemba, Shizuoka 412-8513, Japan under the plasma drug concentration-time curve (AUC) after extravascular (oral, subcutaneous, intramuscular, etc.) delivery and intravenous injection. Thus, it is essential to know the AUC after intravenous injection to estimate $F$, even if an intravenous formulation is not intended as a therapeutic option. Furthermore, clearance (CL) cannot be estimated from subcutaneous injection data alone, but requires comparison of the dose and AUC after intravenous injection. If exposure after extravascular injection is lower than expected in humans, we cannot quantitatively judge which process caused it - absorption or elimination-without intravenous injection data. In fact, several mAbs have been evaluated using intravenous injection in clinical trials even though it would not be used as a therapeutic delivery method $[5,6]$. If $\mathrm{CL}$ and $\mathrm{F}$ could be accurately estimated using only subcutaneous injection data, intravenous evaluations could be skipped in clinical trials. 


\section{Key Points}

A large and comprehensive dataset of linear pharmacokinetic parameters for monoclonal antibodies (mAbs) in humans was constructed using public data on $147 \mathrm{mAbs}$.

Clearance (CL) and bioavailability $(F)$ of mAbs were accurately estimated using only subcutaneous injection data by fixing intercompartmental clearance $(Q)$, volume of distribution in the central compartment $\left(V_{\mathrm{c}}\right)$, and volume of distribution in the peripheral compartment $\left[V_{\mathrm{p}}\right]$ according to the geometric mean of 147 mAbs.

Plasma/serum concentration-time profiles of mAbs after intravenous injection were accurately predicted using estimated CL and the geometric mean of $Q, V_{\mathrm{c}}$, and $V_{\mathrm{p}}$.

Our efficient approach does not require intravenous data to separately estimate $\mathrm{CL}$ and $F$, and can therefore accelerate the clinical development of mAbs.

The linear pharmacokinetic profile of $\mathrm{mAbs}$ is reported to be captured well by the two-compartment model in animals and humans [7, 8]. In two-compartment model parameters (CL, intercompartmental CL $[Q]$, volume of distribution in the central compartment $\left[V_{\mathrm{c}}\right]$, and volume of distribution in the peripheral compartment $\left.\left[V_{\mathrm{p}}\right]\right), \mathrm{CL}$ is determined by the elimination process and $Q, V_{\mathrm{c}}$, and $V_{\mathrm{p}}$ reflect distribution. Due to its large molecular weight and hydrophilic property, the tissue distribution of mAbs is limited to vascular and interstitial spaces [9]. Therefore, mAbs have been reported to show similar volume of distribution at steady state $\left(V \mathrm{~d}_{\mathrm{ss}}\right)$ in cynomolgus monkeys and humans [10]. Moreover, if distribution is similar among mAbs in humans, $Q, V_{\mathrm{c}}$, and $V_{\mathrm{p}}$ can be fixed according to a typical value. Furthermore, if $Q$, $V_{\mathrm{c}}$, and $V_{\mathrm{p}}$ are fixed, CL can be estimated from the slope of the elimination phase ( $\beta$ phase) after subcutaneous injection in linear pharmacokinetics. Since AUC after subcutaneous injection is determined by dose, CL, and $F$, and is not affected by $Q, V_{\mathrm{c}}$, and $V_{\mathrm{p}}$, if CL is estimated from the slope of the elimination phase, then $F$ also can be theoretically estimated from dose and AUC after subcutaneous injection. Thus, CL and F can only be theoretically estimated from the plasma/serum $\mathrm{mAb}$ concentration-time profiles after subcutaneous injection.

In this study, to determine the typical values for each pharmacokinetic parameter (CL, $Q, V_{\mathrm{c}}$, and $V_{\mathrm{p}}$ ), a large dataset (103 mAbs with linear pharmacokinetics and $44 \mathrm{mAbs}$ with nonlinear pharmacokinetics) was first constructed from public data and then analysed. We used this large dataset to investigate the effect of IgG subclasses (IgG1, IgG2, and $\mathrm{IgG} 4$ ) and linearity (linear and nonlinear) on linear pharmacokinetic parameters (CL, $Q, V_{\mathrm{c}}$, and $\mathrm{V}_{\mathrm{p}}$ ) in humans. We then investigated whether subcutaneous injection data alone were sufficient to separately estimate the $\mathrm{CL}$ and $\mathrm{F}$ of mAbs in humans by fixing $Q, V_{\mathrm{c}}$, and $V_{\mathrm{p}}$ as a geometric mean of 147 mAbs.

\section{Materials and Methods}

\subsection{Data Collection}

To construct the dataset for analysis, pharmacokinetic data on mAbs in humans was obtained from literature, patents, presentations at scientific conferences, or information provided by the Pharmaceutical and Medical Devices Agency (PMDA), US Food and Drug Administration (FDA) and European Medicines Agency (EMA). When body weight information was unavailable, a body weight of $75 \mathrm{~kg}$ was applied. Pharmacokinetic data on mAb concentrations in plasma or serum are generally available. In this study, pharmacokinetic data on $\mathrm{mAb}$ concentrations in serum were assumed to be the same as that in plasma. The average values of pharmacokinetic parameters and plasma/serum $\mathrm{mAb}$ concentration-time profiles in humans were collected from published data. The plasma/serum mAb concentration-time profiles in humans after a single intravenous/subcutaneous injection were selected for analysis. These profiles were obtained by scanning figures from data sources using UnGraph 5 (Biosoft, Cambridge, UK). The mAbs with linear pharmacokinetics were categorised in Group A and $\mathrm{mAbs}$ with nonlinear pharmacokinetics were categorised in Group B. In Group B, the reported two-compartment model parameters (CL, $Q, V_{\mathrm{c}}$, and $V_{\mathrm{p}}$ ) were only used if they were available in published data (as estimated by the Michaelis-Menten [MM] model [11] or the target-mediated drug disposition [TMDD] model [12]). The geometric mean of collected parameters for the subclasses, as well as for linear and nonlinear mAbs, were estimated and compared. All mAbs used in this study had a human IgG sequence as a constant region.

\subsection{Estimation of Two-Compartment Model Parameters in Group A}

Group A consisted of $103 \mathrm{mAbs}$ that showed linear pharmacokinetics in humans. Reported values for two-compartment model parameters were used if available in published data. If unavailable, plasma/serum mAb concentration-time profiles were analysed using the traditional two-compartment model with first-order elimination (electronic supplementary Methods) to estimate CL, $Q, V_{\mathrm{c}}$, and $V_{\mathrm{p}}$. 


\subsection{Estimation of Two-Compartment Model Parameters in Group B}

Group B consisted of $44 \mathrm{mAbs}$ that showed nonlinear pharmacokinetics in humans. The accurate estimation of linear pharmacokinetic parameters from nonlinear pharmacokinetics is more complex and requires a reliable dataset. Therefore, as mentioned earlier, only two-compartment model parameters that were estimated by the MM or TMDD model were collected from published data.

\subsection{Estimation of Clearance and Bioavailability After Subcutaneous Injection in Humans}

To estimate $\mathrm{CL}$ and $\mathrm{F}$, the plasma/serum $\mathrm{mAb}$ concentration-time profiles of $25 \mathrm{mAbs}$ in humans after subcutaneous injections were fitted by fixing $Q, V_{\mathrm{c}}$, and $V_{\mathrm{p}}$ with the geometric mean of 147 mAbs (103 mAbs in Group A and 44 $\mathrm{mAbs}$ in Group B). These $25 \mathrm{mAbs}$ were selected because of their linear pharmacokinetics and the availability of plasma/ serum $\mathrm{mAb}$ concentration-time profiles after both intravenous and subcutaneous injection. Twenty of the $25 \mathrm{mAbs}$ were included in Group A. The estimated CL and $F$ were compared with observed values. The plasma/serum $\mathrm{mAb}$ concentration-time profiles after subcutaneous injection were fitted to the traditional two-compartment model with first-order absorption and elimination (electronic supplementary Methods).

\subsection{Prediction of Plasma/Serum Monoclonal Antibody (mAb) Concentration-Time Profiles After Intravenous Injection in Humans}

Using the estimated CL and geometric mean of $Q, V_{\mathrm{c}}$, and $V_{\mathrm{p}}$, the plasma/serum mAb concentration-time profiles of $25 \mathrm{mAbs}$ after intravenous injection in humans were then simulated. The dose used in the simulation was the same as that used in the clinical study. Simulated profiles were compared with observed values.

\subsection{Analysis}

All fittings and simulations were performed using SAAMII software (The Epsilon Group, Charlottesville, VA, USA). The Rosenbrock method was used as an integrator and all fittings were performed using the default setting in SAAMII. Relative weight $\left(1 / \mathrm{y}^{\wedge} 2\right)$ was used in all fittings. All figures and statistical analyses were prepared using GraphPad Prism 7 (GraphPad Software, San Diego, CA, USA). Since it has been reported that pharmacokinetic parameters show lognormal distribution [13, 14], this was assumed for each parameter in this study.

\section{Results}

\subsection{Estimation of the Geometric Mean of Linear Pharmacokinetic Parameters of $m A$ bs in Humans}

A total of 147 mAbs (103 mAbs with linear pharmacokinetics [Group A] and $44 \mathrm{mAbs}$ with nonlinear pharmacokinetics [Group B]) were selected as a dataset to estimate the geometric mean of each pharmacokinetic parameter. Collected linear pharmacokinetic parameters in Groups A and $\mathrm{B}$ are summarised in electronic supplementary Tables 1 and 2. The estimated geometric mean of CL, $Q, V_{\mathrm{c}}$, and $V_{\mathrm{p}}$ for all $147 \mathrm{mAbs}$, divided into Groups A and B, are summarised in Table 1. In both Groups A and B, the distribution of each pharmacokinetic parameter was similar (Fig. 1), indicating that nonlinear pharmacokinetics does not affect linear twocompartment model parameters estimated by MM or TMDD model analysis. There were 101 IgG1 (74 in Group A and 27 in Group B), 24 IgG2 (14 in Group A and 10 in Group B), and 22 IgG4 (15 in Group A and 7 in Group B) subclasses in the dataset. The estimated geometric mean of CL, $Q, V_{\mathrm{c}}$, and $V_{\mathrm{p}}$ for $\mathrm{mAbs}$ in $\mathrm{IgG1}, \operatorname{IgG} 2$, and $\mathrm{IgG} 4$ are summarised in Table 1. Each pharmacokinetic parameter was similarly distributed in the IgG subclasses (Fig. 2), indicating that the IgG subclass does not affect linear two-compartment model parameters in humans. Thus, all datasets (IgG subclasses and linearity) were combined to estimate the geometric mean of pharmacokinetic parameters of mAbs in humans.

\subsection{Estimation of Clearance and Subcutaneous Bioavailability of mAbs in Humans}

A total of $25 \mathrm{mAbs}$ were selected because of their linear pharmacokinetics and the availability of plasma/serum $\mathrm{mAb}$ concentration-time profiles after both intravenous and subcutaneous injection as a dataset to estimate $\mathrm{CL}$ and $F$. They consisted of $16 \mathrm{IgG} 1,4 \mathrm{IgG} 2$, and $5 \mathrm{IgG} 4$ subclasses. Plasma/serum mAb concentration-time profiles after subcutaneous injection were fitted by fixing $Q(8.77 \mathrm{~mL} /$ day/ $\mathrm{kg}), V_{\mathrm{c}}(44.2 \mathrm{~mL} / \mathrm{kg})$, and $V_{\mathrm{p}}(36.7 \mathrm{~mL} / \mathrm{kg})$ with geometric mean, and $\mathrm{CL}$ and $\mathrm{F}$ were estimated. Observed and estimated $C L$ and $F$ for the $25 \mathrm{mAbs}$ are summarised in Table 2 . The estimated values were plotted with the observed values (Fig. 3a, b). As shown in Fig. 3a, CL of 23/25 mAbs (92\%) was successfully estimated within 1.3-fold of the observed values. CL of all mAbs (100\%) was estimated within 2 -fold of the observed values. As shown in Fig. 3b, F of 21/25 mAbs (84\%) and 25/25 mAbs (100\%) was successfully estimated within 1.3- and 1.5-fold of the observed values, respectively. Although the largest IgG subclass for these 25 
Table 1 Geometric mean of $\mathrm{CL}, \mathrm{Q}, \mathrm{V}_{\mathrm{c}}$, and $\mathrm{V}_{\mathrm{p}}$ of $\mathrm{mAbs}$ in humans

\begin{tabular}{|c|c|c|c|c|c|}
\hline Dataset & No. of mAbs & $\begin{array}{l}\mathrm{CL} \\
\mathrm{mL} / \text { day/kg }\end{array}$ & $\begin{array}{l}Q \\
\mathrm{~mL} / \text { day/kg }\end{array}$ & $\begin{array}{l}V_{\mathrm{c}} \\
\mathrm{mL} / \mathrm{kg}\end{array}$ & $\begin{array}{l}V_{\mathrm{p}} \\
\mathrm{mL} / \mathrm{kg}\end{array}$ \\
\hline Total & 147 & $\begin{array}{l}3.32 \\
(1.11-12.6)\end{array}$ & $\begin{array}{l}8.77 \\
(1.26-86.3)\end{array}$ & $\begin{array}{l}44.2 \\
(21.3-86.7)\end{array}$ & $\begin{array}{l}36.7 \\
(15.6-113)\end{array}$ \\
\hline Group A & 103 & $\begin{array}{l}3.34 \\
(1.27-12.6)\end{array}$ & $\begin{array}{l}8.62 \\
(1.26-86.3)\end{array}$ & $\begin{array}{l}43.5 \\
(21.4-71.6)\end{array}$ & $\begin{array}{l}37.6 \\
(15.6-113)\end{array}$ \\
\hline Group B & 44 & $\begin{array}{l}3.26 \\
(1.11-10.1)\end{array}$ & $\begin{array}{l}9.11 \\
(1.76-44.6)\end{array}$ & $\begin{array}{l}45.7 \\
(21.3-86.7)\end{array}$ & $\begin{array}{l}34.8 \\
(16.3-80.0)\end{array}$ \\
\hline IgG1 & 101 & $\begin{array}{l}3.55 \\
(1.17-12.6)\end{array}$ & $\begin{array}{l}8.96 \\
(1.26-86.3)\end{array}$ & $\begin{array}{l}44.2 \\
(21.4-71.6)\end{array}$ & $\begin{array}{l}37.0 \\
(15.6-113)\end{array}$ \\
\hline IgG2 & 24 & $\begin{array}{l}2.87 \\
(1.11-10.1)\end{array}$ & $\begin{array}{l}8.45 \\
(3.70-44.6)\end{array}$ & $\begin{array}{l}42.7 \\
(21.3-58.8)\end{array}$ & $\begin{array}{l}36.3 \\
(16.8-76.3)\end{array}$ \\
\hline $\mathrm{IgG} 4$ & 22 & $\begin{array}{l}2.85 \\
(1.41-5.52)\end{array}$ & $\begin{array}{l}8.23 \\
(2.35-24.3)\end{array}$ & $\begin{array}{l}45.7 \\
(26.7-86.7)\end{array}$ & $\begin{array}{l}36.1 \\
(16.3-80.0)\end{array}$ \\
\hline
\end{tabular}

Data in parentheses indicate the range of the observed values

$C L$ clearance, $Q$ intercompartmental clearance, $V_{c}$ volume of distribution in the central compartment, $V_{p}$ volume of distribution in the peripheral compartment, $m A b s$ monoclonal antibodies, $\operatorname{Ig} G$ immunoglobulin G

mAbs is $\operatorname{IgG} 1$, there was no apparent difference in estimation accuracy among the three $\operatorname{IgG}$ subclasses.

\subsection{Prediction of Plasma/Serum mAb Concentration-Time Profiles After Intravenous Injection in Humans}

Using estimated CL and geometric mean of $Q, V_{\mathrm{c}}$, and $V_{\mathrm{p}}$, we simulated the plasma/serum mAb concentration timeprofiles after intravenous injection for $25 \mathrm{mAbs}$. As shown in electronic supplementary Fig. 1, the predicted plasma/ serum mAb concentration-time profiles were mostly consistent with the observed values. The relationship between the observed and predicted plasma/serum $\mathrm{mAb}$ concentrations is shown in Fig. 4. As a result, $90.8 \%$ and $99.7 \%$ of time points were accurately predicted within 1.5- and 2-fold of the observed values, respectively. Only one time point (final time point for Risankizumab/ABBV-066) was predicted to be over 2-fold of the observed value.

\section{Discussion}

In this study, we investigated whether the CL and F of mAbs can be separately estimated using only subcutaneous injection data in humans. Analysis was conducted using a large and comprehensive dataset constructed from a total of 147 mAbs. To be best of our knowledge, this is the largest dataset of pharmacokinetic parameters for mAbs ever reported. It enabled us to investigate the effect of two factors- $-\mathrm{IgG}$ subclasses and pharmacokinetic linearity_on the linear pharmacokinetic parameters of mAbs in humans.
First, we investigated the effect of IgG subclasses. Previously, Walker et al., examined the effect of IgG subclasses of mAbs on pharmacokinetics in rats and cynomolgus monkeys [15]. They compared IgG1 and IgG2 using four mAbs with different amino acid sequences in the variable region and concluded that the difference in IgG subclass had no significant impact on pharmacokinetics. Furthermore, Tabrizi et al. reported no significant impact of IgG subclass (IgG1 vs. IgG4) on the pharmacokinetics of mAbs in mice, dogs, and cynomolgus monkeys [16]. We and other groups have reported that the pharmacokinetics of mAbs in humans can be accurately predicted using the allometric scaling approach with cynomolgus monkeys [17-19]. Thus, the impact of IgG subclasses should also be minimal in humans; however, evidence in humans has never been demonstrated. To appropriately investigate their effect on pharmacokinetics in humans, we would need to directly compare the pharmacokinetics of IgG subclasses using mAbs with the same amino acid sequence in the variable region. However, since this would be difficult in humans for economic and ethical reasons, it is essential to conduct a comprehensive analysis using a large dataset. In this study, we first demonstrated the impact of IgG subclasses on the pharmacokinetics of mAbs in humans using a large dataset. Our results indicate that IgG subclasses have no significant impact on the linear pharmacokinetic parameters of mAbs in humans.

The second factor we investigated was the effect of linearity on linear pharmacokinetic parameters in humans. This is the first report to examine the effect of linearity on the linear pharmacokinetic parameters of mAbs. Generally, mAbs are classified into two types-those with linear pharmacokinetics and those with nonlinear 
Table 2 Observed and estimated CL and F of $25 \mathrm{mAbs}$ in humans

\begin{tabular}{|c|c|c|c|c|c|c|c|}
\hline \multirow[t]{3}{*}{ Antibody } & \multirow[t]{3}{*}{ Target } & \multirow[t]{3}{*}{ Subclass } & \multicolumn{2}{|l|}{ Observed } & \multicolumn{2}{|l|}{ Estimated } & \multirow[t]{3}{*}{ Reference } \\
\hline & & & CL & $F$ & CL & $\mathrm{F}$ & \\
\hline & & & $\mathrm{mL} /$ day $/ \mathrm{kg}$ & $\%$ & $\mathrm{~mL} /$ day $/ \mathrm{kg}$ & $\%$ & \\
\hline Adalimumab & $\mathrm{TNF} \alpha$ & IgG1 & 3.43 & 52.0 & 4.22 & 67.5 & {$[31]$} \\
\hline ANB020 & IL-33 & IgG1 & 7.20 & 29.0 & 6.18 & 24.8 & {$[32]$} \\
\hline Belimumab & BLyS & IgG1 & 3.02 & 77.5 & 2.43 & 93.5 & [33] \\
\hline Burosumab/KRN23 & FGF23 & IgG1 & 3.43 & 128 & 3.19 & 97.1 & [34] \\
\hline Canakinumab & IL-1 $\beta$ & IgG1 & 2.80 & 66.5 & 2.72 & 88.2 & {$[35]$} \\
\hline CNTO5825 & IL-13 & IgG1 & 2.31 & 75.0 & 2.95 & 84.6 & {$[36]$} \\
\hline Eptinezumab/ALD403 & CGRP & IgG1 & 2.25 & 71.7 & 2.72 & 88.9 & {$[37]$} \\
\hline Golimumab & $\mathrm{TNF} \alpha$ & IgG1 & 5.18 & 51.1 & 5.62 & 44.7 & {$[38]$} \\
\hline Guselkumab/CNTO1959 & IL-23 & IgG1 & 4.61 & 60.1 & 4.27 & 50.7 & {$[5]$} \\
\hline MEDI-528 & IL-9 & IgG1 & 1.96 & 79.0 & 2.14 & 85.7 & [39] \\
\hline Mepolizumab & IL-5 & IgG1 & 2.92 & 74.0 & 3.42 & 104 & [40] \\
\hline NNC0114-0005 & IL-21 & IgG1 & 3.15 & 60.0 & 4.03 & 43.2 & [41] \\
\hline Risankizumab/ABBV-066 & IL-23 & IgG1 & 3.80 & 62.7 & 2.49 & 66.1 & {$[42]$} \\
\hline Secukinumab & IL-17A & IgG1 & 2.09 & 55.0 & 3.33 & 68.6 & {$[43]$} \\
\hline Sirukumab/CNTO136 & IL-6 & IgG1 & 5.11 & 92.4 & 4.39 & 77.0 & [44] \\
\hline Tildrakizumab/MK-3222 & IL-23 & IgG1 & 2.20 & 73.0 & 2.47 & 94.0 & {$[45]$} \\
\hline AMG403 & NGF & IgG2 & 3.39 & 73.6 & 3.30 & 92.8 & [46] \\
\hline Gevokizumab & IL-1 $\beta$ & $\mathrm{IgG} 2$ & 2.46 & 69.0 & 1.90 & 75.2 & [47] \\
\hline RN317/PF-05335810 & PCSK9 & $\mathrm{IgG} 2$ & 4.43 & 61.9 & 5.37 & 59.0 & [48] \\
\hline Tezepelumab/AMG157/MEDI9929 & TSLP & IgG2 & 2.52 & 81.3 & 2.73 & 96.4 & [49] \\
\hline ANB019 & IL-36R & IgG4 & 2.96 & 95.0 & 2.70 & 87.7 & {$[50]$} \\
\hline BITS7201A & IL-13/17 & IgG4 & 2.43 & 109 & 3.00 & 95.1 & {$[51]$} \\
\hline Emicizumab/ACE910 & $\mathrm{FIXa/FX}$ & IgG4 & 3.02 & 85.5 & 2.58 & 71.1 & {$[52]$} \\
\hline Tralokinumab/CAT-354 & IL-13 & IgG4 & 2.93 & 80.0 & 3.02 & 95.7 & {$[53]$} \\
\hline Olokizumab & IL-6 & IgG4 & 1.99 & 84.2 & 1.88 & 77.8 & {$[54]$} \\
\hline
\end{tabular}

Twenty-five mAbs were selected due to their linear pharmacokinetics and the availability of plasma/serum $\mathrm{mAb}$ concentration-time profiles after intravenous and subcutaneous injection

$C L$ clearance, $F$ bioavailability, $T N F$ tumour necrosis factor, $I L$ interleukin, $F G F$ fibroblast growth factor, $N G F$ nerve growth factor, $P C S K 9$ proprotein convertase subtilisin kexin $9, \operatorname{Ig} G$ immunoglobulin $\mathrm{G}$ pharmacokinetics. In most cases, the nonlinear pharmacokinetics of mAbs is caused by the plasma/serum mAb concentration-dependent saturation of target-mediated elimination. To quantitatively and separately estimate both linear and nonlinear pharmacokinetic parameters using nonlinear pharmacokinetic data, plasma/serum $\mathrm{mAb}$ concentration-time profiles have been analysed using the MM or TMDD model. In this study, the MM or TMDD model-derived linear pharmacokinetic parameters of mAbs with nonlinear pharmacokinetics were collected from published data and compared with those for mAbs with linear pharmacokinetics. As a result, we found that linearity had no impact on the linear pharmacokinetic parameters. Thus, although we estimated CL and F of mAbs with linear pharmacokinetics using only subcutaneous injection data in humans in this study, this approach could also be used to estimate $\mathrm{CL}$ and $\mathrm{F}$ of $\mathrm{mAbs}$ with nonlinear pharmacokinetics. We will further investigate this possibility in the future using a large dataset of mAbs with nonlinear pharmacokinetics in humans. In this study, since we demonstrated that IgG subclasses and linearity had no significant effect on the linear pharmacokinetic parameters using a large constructed dataset, we combined the data for all $147 \mathrm{mAbs}$ to estimate the geometric mean of each pharmacokinetic parameter.

The estimated geometric means of CL, $Q, V_{\mathrm{c}}$, and $V_{\mathrm{p}}$ of $147 \mathrm{mAbs}$ in humans were $3.32 \mathrm{~mL} /$ day $/ \mathrm{kg}, 8.77 \mathrm{~mL} /$ day/ $\mathrm{kg}, 44.2 \mathrm{~mL} / \mathrm{kg}$, and $36.7 \mathrm{~mL} / \mathrm{kg}$. By fixing $Q, V_{\mathrm{c}}$, and $V_{\mathrm{p}}$ as a geometric mean, $\mathrm{CL}$ and $\mathrm{F}$ of mAbs in humans were estimated from plasma/serum mAb concentration-time profiles after subcutaneous injection. Using this approach, we accurately estimated CL and F of $25 \mathrm{mAbs}$ in humans (CL: 

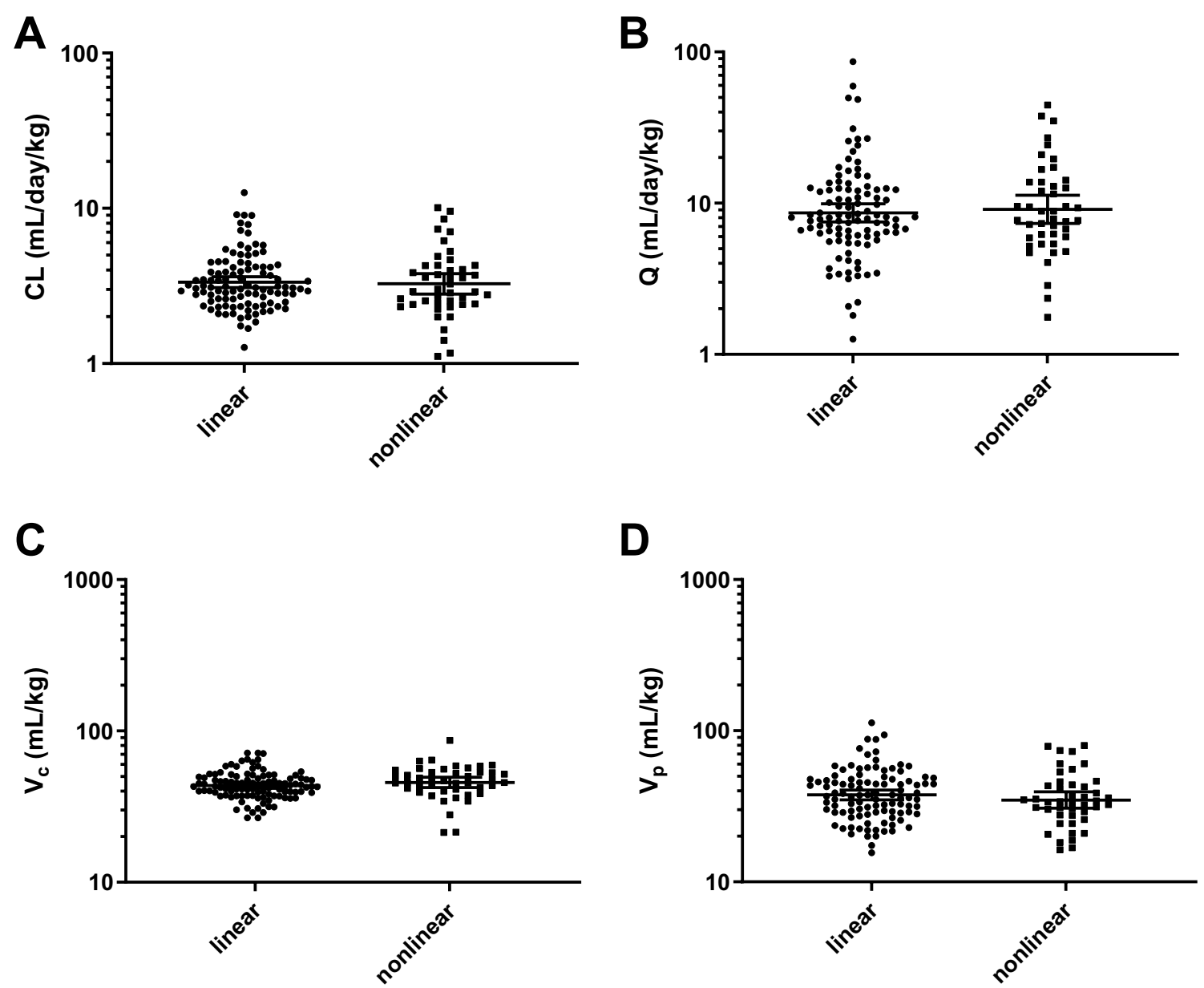

Fig. 1 Effect of linearity on the distribution of a CL, b $Q, \mathbf{c} V_{\mathrm{c}}$, and d $V_{\mathrm{p}}$. Geometric mean with $95 \%$ confidence interval is shown. Closed circles indicate the linear pharmacokinetic parameters derived from mAbs with linear pharmacokinetics, and closed squares indicate the linear pharmacokinetic parameters derived from mAbs with nonlinear

$92 \%$ and $100 \%$ within 1.3 - and 2-fold of the observed values, F: $84 \%$ and $100 \%$ within $1.3-$ and 1.5 -fold of the observed values).

The pharmacokinetics of mAbs in humans is influenced by several factors, such as body size, age, plasma serum albumin/IgG levels, or antidrug antibodies [20, 21]. Gill et al. summarised the reported interindividual variability (coefficient of variation [CV]) of CL for several mAbs in clinical trials analysed by population pharmacokinetics [20]. In this report, most of the mAbs showed over $30 \% \mathrm{CV}$ of $\mathrm{CL}$. Gill et al. also reported that the interindividual variability in subcutaneous $\mathrm{F}$ of mAbs in humans was around $40-50 \%$ of the CV [20]. Considering the interindividual variability of $\mathrm{CL}$ and $\mathrm{F}$ of $\mathrm{mAbs}$ in humans, the predictability of our approach could be acceptable in the development of mAbs. Furthermore, $90.8 \%$ and $99.7 \%$ of plasma/ serum $\mathrm{mAb}$ concentration-time profiles after intravenous

pharmacokinetics based on the MM or TMDD models. mAbs monoclonal antibodies, $M M$ Michaelis-Menten, TMDD target-mediated drug disposition, $C L$ clearance, $Q$ intercompartmental clearance, $V_{c}$ volume of distribution in the central compartment, $V_{p}$ volume of distribution in the peripheral compartment

injection were successfully predicted within 1.5 - and 2-fold of the observed values in this study. Generally, prediction of the plasma/serum concentration-time profile is more difficult compared with that of CL and F because the plasma/ serum concentration-time profile is influenced by all pharmacokinetic parameters. Prediction of the later part of the plasma/serum mAb concentration-time profile is especially challenging because it requires the highly accurate prediction of both elimination and distribution. As a result, in this study, although it would normally be very challenging, our approach accurately predicted plasma/serum mAb concentration-time profiles after intravenous injection from subcutaneous injection data.

Recently, technologies such as the recycling antibody [22, 23], sweeping antibody [24, 25], and hyaluronidase [26] are being developed to facilitate the subcutaneous injection of mAbs by reducing the effective dosage or increasing the 


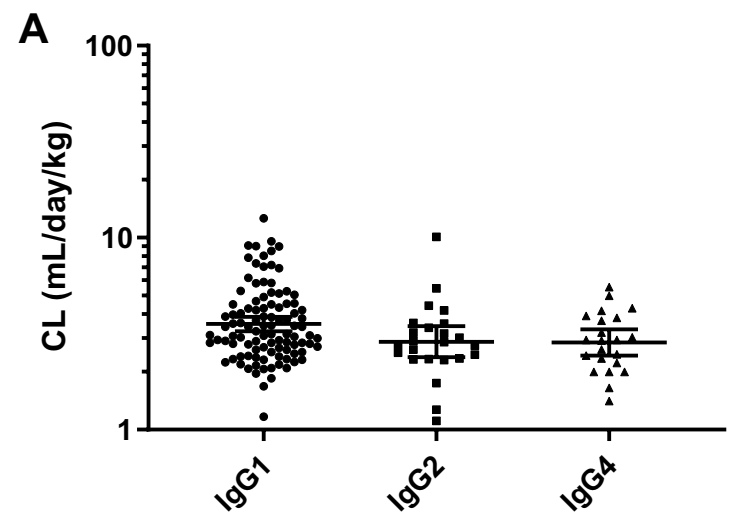

C

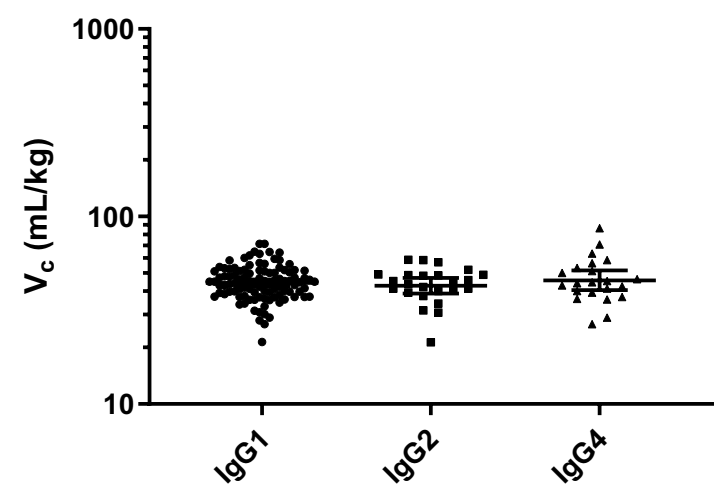

Fig. 2 Effect of $\mathrm{IgG}$ subclasses on the distribution of a CL, b $Q, \mathbf{c} V_{\mathrm{c}}$, and d $V_{\mathrm{p}}$. Geometric mean with $95 \%$ confidence interval is shown. Closed circles, squares and triangles indicate the linear pharmacokinetic parameters of the $\operatorname{IgG1}, 2$, and 4 subclasses. $\operatorname{Ig} G$ immunoglobu-

A

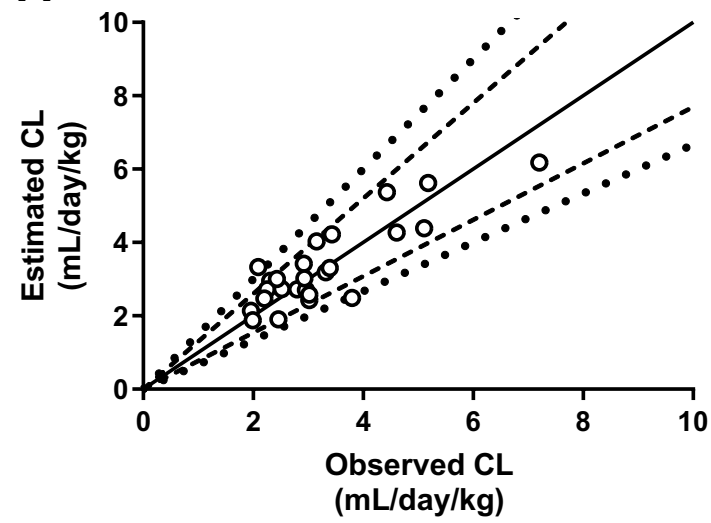

Fig. 3 Estimation of a CL and $\mathbf{b} F$ after subcutaneous injection of 25 mAbs in humans. Open circles indicate the observed and estimated $\mathrm{CL}$ of $25 \mathrm{mAbs}$; open squares indicate the observed and estimated $\mathrm{F}$ of $25 \mathrm{mAbs}$; solid line indicates the $100 \%$ estimation; and dashed
B

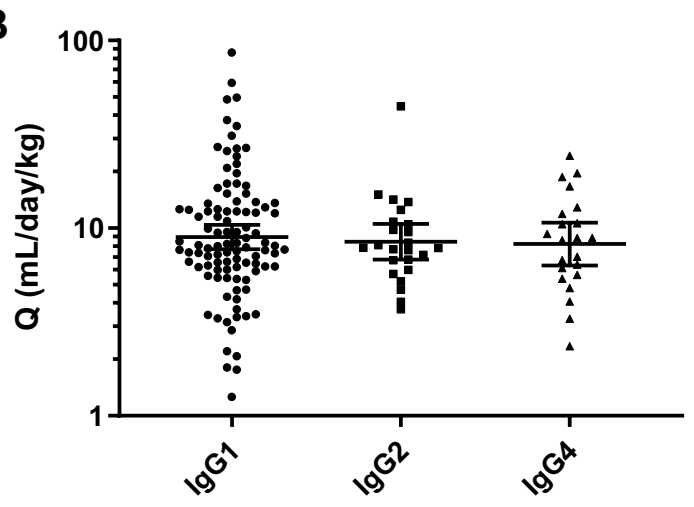

D

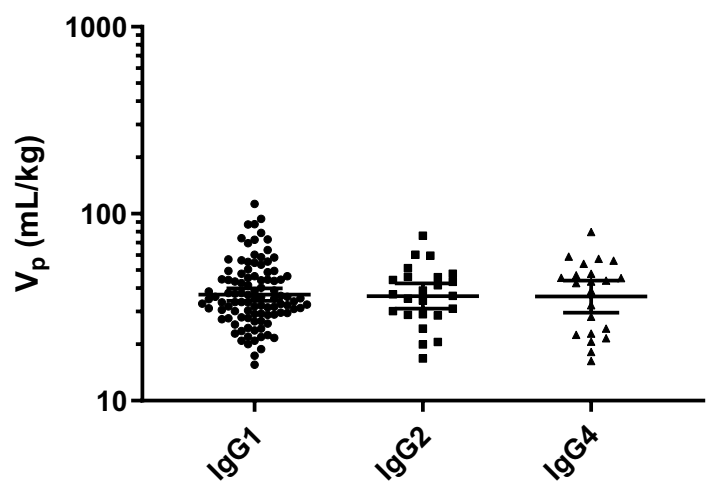

lin G, $C L$ clearance, $Q$ intercompartmental clearance, $V_{c}$ volume of distribution in the central compartment, $V_{p}$ volume of distribution in the peripheral compartment

B

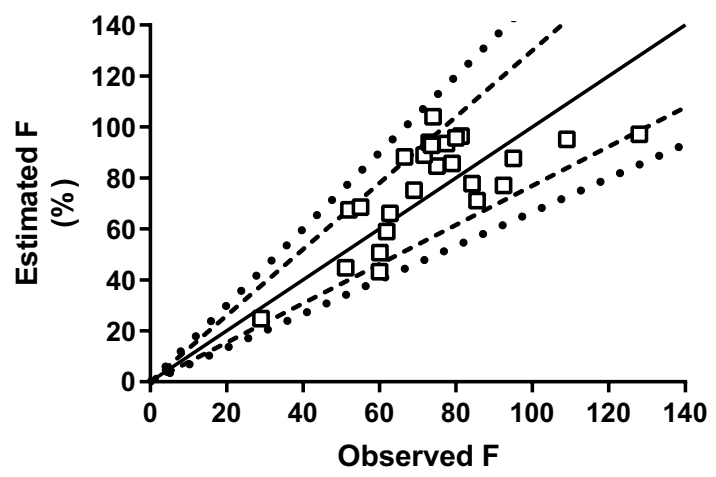

(\%)

lines and dotted lines indicate the 1.3- and 1.5-fold estimations, respectively. $C L$ clearance, $F$ bioavailability, $m A b s$ monoclonal antibodies 


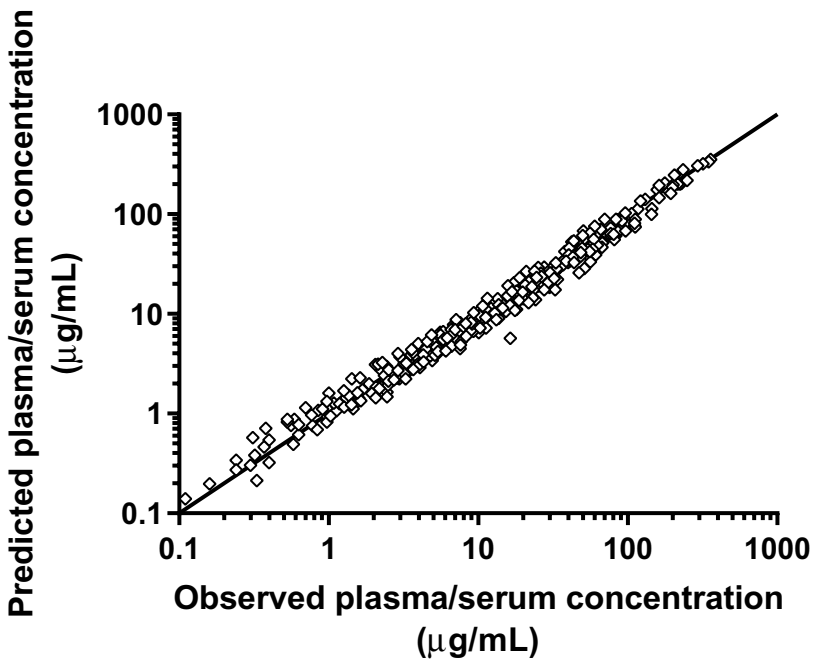

Fig. 4 Scatter plot of predicted and observed plasma/serum mAb concentrations. Open diamonds indicate the observed and predicted plasma/serum mAb concentrations, and solid line indicates the $100 \%$ prediction line. $m A b$ monoclonal antibody

injectable volume. Our approach should be compatible with these technologies since they only affect CL and/or F of mAbs after subcutaneous injection and show similar tissue distribution to normal mAbs. Clinical data on these technologies will be further analysed to investigate the applicability of our approach. While this study focuses on subcutaneous injection of mAbs, other injection routes, such as intramuscular [27, 28] and intraperitoneal [29, 30], are also used in the clinic. Since injection routes do not affect the systemic tissue distribution of mAbs, our approach can be expanded to include intramuscular and intraperitoneal injection in the future. Our approach can also be used with multiple technologies and in a variety of clinical situations.

\section{Conclusion}

This study demonstrated an approach for estimating CL and $\mathrm{F}$ after subcutaneous injection in humans using only subcutaneous injection data. This means that an intravenous injection will no longer be required to separately estimate the $\mathrm{CL}$ and $\mathrm{F}$ of mAbs in clinical trials. Our approach has the potential to change the way clinical trials are designed and to accelerate the development of mAbs.

Supplementary Information The online version contains supplementary material available at https://doi.org/10.1007/s40262-021-01023-z.

\section{Declarations}

Funding This work was fully supported by Chugai Pharmaceutical Co. Ltd.

Conflict of Interest Kenta Haraya and Tatsuhiko Tachibana declare they have no potential conflicts of interest that might be relevant to the contents of this manuscript.

Ethics Approval Not applicable.

Consent to Participate Not applicable.

Consent for Publication Not applicable.

Availability of Data and Material Not applicable.

Code Availability Not applicable.

Author Contributions $\mathrm{KH}$ and TT conducted data collection and analysis and wrote the manuscript.

Open Access This article is licensed under a Creative Commons Attribution-NonCommercial 4.0 International License, which permits any non-commercial use, sharing, adaptation, distribution and reproduction in any medium or format, as long as you give appropriate credit to the original author(s) and the source, provide a link to the Creative Commons licence, and indicate if changes were made. The images or other third party material in this article are included in the article's Creative Commons licence, unless indicated otherwise in a credit line to the material. If material is not included in the article's Creative Commons licence and your intended use is not permitted by statutory regulation or exceeds the permitted use, you will need to obtain permission directly from the copyright holder. To view a copy of this licence, visit http://creativecommons.org/licenses/by-nc/4.0/.

\section{References}

1. Singh S, Kumar NK, Dwiwedi P, Charan J, Kaur R, Sidhu P, et al. Monoclonal antibodies: a review. Curr Clin Pharmacol. 2018;13(2):85-99. https://doi.org/10.2174/157488471266617 0809124728 .

2. Kaplon H, Muralidharan M, Schneider Z, Reichert JM. Antibodies to watch in 2020. mAbs. 2020;12(1):1703531. https://doi.org/10. 1080/19420862.2019.1703531.

3. Daugherty AL, Mrsny RJ. Formulation and delivery issues for monoclonal antibody therapeutics. Adv Drug Deliv Rev. 2006;58(5-6):686-706. https://doi.org/10.1016/j.addr.2006.03. 011.

4. Viola M, Sequeira J, Seica R, Veiga F, Serra J, Santos AC, et al. Subcutaneous delivery of monoclonal antibodies: how do we get there? J Control Release. 2018;286:301-14. https://doi.org/10. 1016/j.jconrel.2018.08.001.

5. Zhuang Y, Calderon C, Marciniak SJ Jr, Bouman-Thio E, Szapary P, Yang TY, et al. First-in-human study to assess guselkumab (anti-IL-23 mAb) pharmacokinetics/safety in healthy subjects and patients with moderate-to-severe psoriasis. Eur J Clin Pharmacol. 2016;72(11):1303-10. https://doi.org/10. 1007/s00228-016-2110-5.

6. Zhang X, Peyret T, Gosselin NH, Marier JF, Imel EA, Carpenter TO. Population pharmacokinetic and pharmacodynamic analyses from a 4-month intradose escalation and its subsequent 
12-month dose titration studies for a human monoclonal antiFGF23 antibody (KRN23) in adults with X-linked hypophosphatemia. J Clin Pharmacol. 2016;56(4):429-38. https://doi.org/ 10.1002/jcph.611.

7. Kakkar T, Ma M, Zhuang Y, Patton A, Hu Z, Mounho B. Pharmacokinetics and safety of a fully human hepatocyte growth factor antibody, AMG 102, in cynomolgus monkeys. Pharm Res. 2007;24(10):1910-8. https://doi.org/10.1007/s11095-007-9316-2.

8. Han K, Peyret T, Marchand M, Quartino A, Gosselin NH, Girish $\mathrm{S}$, et al. Population pharmacokinetics of bevacizumab in cancer patients with external validation. Cancer Chemother Pharmacol. 2016;78(2):341-51. https://doi.org/10.1007/s00280-016-3079-6.

9. Baxter LT, Zhu H, Mackensen DG, Jain RK. Physiologically based pharmacokinetic model for specific and nonspecific monoclonal antibodies and fragments in normal tissues and human tumor xenografts in nude mice. Can Res. 1994;54(6):1517-28.

10. Dong JQ, Salinger DH, Endres CJ, Gibbs JP, Hsu CP, Stouch BJ, et al. Quantitative prediction of human pharmacokinetics for monoclonal antibodies: retrospective analysis of monkey as a single species for first-in-human prediction. Clin Pharmacokinet. 2011;50(2):131-42. https://doi.org/10.2165/11537430-00000 0000-00000.

11. Frey N, Grange S, Woodworth T. Population pharmacokinetic analysis of tocilizumab in patients with rheumatoid arthritis. J Clin Pharmacol. 2010;50(7):754-66. https://doi.org/10.1177/ 0091270009350623.

12. Vugmeyster Y, Rohde C, Perreault M, Gimeno RE, Singh P. Agonistic TAM-163 antibody targeting tyrosine kinase receptor-B: applying mechanistic modeling to enable preclinical to clinical translation and guide clinical trial design. mAbs. 2013;5(3):37383. https://doi.org/10.4161/mabs.23826.

13. Mizuta E, Tsubotani A. Preparation of mean drug concentrationtime curves in plasma. A study on the frequency distribution of pharmacokinetic parameters. Chem Pharm Bull. 1985;33(4):162032. https://doi.org/10.1248/cpb.33.1620.

14. Kato M, Tachibana T, Ito K, Sugiyama Y. Evaluation of methods for predicting drug-drug interactions by Monte Carlo Simulation. Drug Metab Pharmacokinet. 2003;18(2):121-7. https://doi.org/10. 2133/dmpk.18.121.

15. Walker KW, Salimi-Moosavi H, Arnold GE, Chen Q, Soto M, Jacobsen FW, et al. Pharmacokinetic comparison of a diverse panel of non-targeting human antibodies as matched IgG1 and $\mathrm{IgG} 2$ isotypes in rodents and non-human primates. PLoS ONE. 2019;14(5):e0217061. https://doi.org/10.1371/journal.pone.02170 61.

16. Tabrizi M, Neupane D, Elie SE, Shankaran H, Juan V, Zhang S, et al. Pharmacokinetic properties of humanized IgG1 and IgG4 antibodies in preclinical species: translational evaluation. AAPS J. 2019;21(3):39. https://doi.org/10.1208/s12248-019-0304-3.

17. Haraya K, Tachibana T, Nezu J. Quantitative prediction of therapeutic antibody pharmacokinetics after intravenous and subcutaneous injection in human. Drug Metab Pharmacokinet. 2017;32(4):208-17. https://doi.org/10.1016/j.dmpk.2017.05.002.

18. Haraya K, Tachibana T. Simple approach to accurately predict pharmacokinetics of therapeutic monoclonal antibodies after subcutaneous injection in humans. Clin Pharmacokinet. 2021;60(1):111-20. https://doi.org/10.1007/s40262-020-00917-8.

19. Oitate M, Masubuchi N, Ito T, Yabe Y, Karibe T, Aoki T, et al. Prediction of human pharmacokinetics of therapeutic monoclonal antibodies from simple allometry of monkey data. Drug Metab Pharmacokinet. 2011;26(4):423-30. https://doi.org/10.2133/ dmpk.dmpk-11-rg-011.

20. Gill KL, Machavaram KK, Rose RH, Chetty M. Potential sources of inter-subject variability in monoclonal antibody pharmacokinetics. Clin Pharmacokinet. 2016;55(7):789-805. https://doi.org/ 10.1007/s40262-015-0361-4.
21. Bensalem A, Ternant D. Pharmacokinetic variability of therapeutic antibodies in humans: a comprehensive review of population pharmacokinetic modeling publications. Clin Pharmacokinet. 2020;59(7):857-74. https://doi.org/10.1007/s40262-020-00874-2.

22. Igawa T, Ishii S, Tachibana T, Maeda A, Higuchi Y, Shimaoka $\mathrm{S}$, et al. Antibody recycling by engineered $\mathrm{pH}$-dependent antigen binding improves the duration of antigen neutralization. Nat Biotechnol. 2010;28(11):1203-7. https://doi.org/10.1038/nbt.1691.

23. Fukuzawa T, Sampei Z, Haraya K, Ruike Y, Shida-Kawazoe M, Shimizu Y, et al. Long lasting neutralization of C5 by SKY59, a novel recycling antibody, is a potential therapy for complementmediated diseases. Sci Rep. 2017;7(1):1080. https://doi.org/10. 1038/s41598-017-01087-7.

24. Haraya K, Tachibana T, Igawa T. Improvement of pharmacokinetic properties of therapeutic antibodies by antibody engineering. Drug Metab Pharmacokinet. 2019;34(1):25-41. https://doi.org/10. 1016/j.dmpk.2018.10.003.

25. Haraya K, Tachibana T, Iwayanagi Y, Maeda A, Ozeki K, Nezu $\mathrm{J}$, et al. PK/PD analysis of a novel $\mathrm{pH}$-dependent antigen-binding antibody using a dynamic antibody-antigen binding model. Drug Metab Pharmacokinet. 2016;31(2):123-32. https://doi.org/10. 1016/j.dmpk.2015.12.007.

26. Locke KW, Maneval DC, LaBarre MJ. ENHANZE® drug delivery technology: a novel approach to subcutaneous administration using recombinant human hyaluronidase PH20. Drug Delivery. 2019;26(1):98-106. https://doi.org/10.1080/10717544.2018. 1551442.

27. Subramanian GM, Cronin PW, Poley G, Weinstein A, Stoughton $\mathrm{SM}$, Zhong J, et al. A phase 1 study of PAmAb, a fully human monoclonal antibody against Bacillus anthracis protective antigen, in healthy volunteers. Clin Infect Dis. 2005;41(1):12-20. https://doi.org/10.1086/430708.

28. Domachowske JB, Khan AA, Esser MT, Jensen K, Takas T, Villafana T, et al. Safety, tolerability and pharmacokinetics of MEDI8897, an extended half-life single-dose respiratory syncytial virus prefusion F-targeting monoclonal antibody administered as a single dose to healthy preterm infants. Pediatr Infect Dis J. 2018;37(9):886-92. https://doi.org/10.1097/INF.0000000000 001916.

29. Knödler M, Körfer J, Kunzmann V, Trojan J, Daum S, Schenk M, et al. Randomised phase II trial to investigate catumaxomab (antiEpCAM $\times$ anti-CD3) for treatment of peritoneal carcinomatosis in patients with gastric cancer. Br J Cancer. 2018;119(3):296-302. https://doi.org/10.1038/s41416-018-0150-6.

30. Coward J, Dizon D, Kichenadasse G, Harnett P, Moore K, Barve $M$ et al. Abstract CT091: Phase I study of intraperitoneal TRX-E002-1 in patients with persistent or recurrent ovarian cancer, fallopian tube cancer or primary peritoneal cancer: Results of doseescalation phase. Cancer research. 2019;79(13 Suppl):CT091-CT. https://doi.org/10.1158/1538-7445.am2019-ct091.

31. Pharmaceutical and Medical Devices Agency (PMDA). Adalimumab (Humira). 2008. https://www.pmda.go.jp/drugs/2008/ P200800019/index.html. Accessed 1 Mar 2020.

32. Kenney B, Los G, Marino MH, Londei M. A Phase 1 Study of ANB020, an Anti-IL-33 Monoclonal Antibody, in Healthy Volunteers. American Academy of Allergy, Asthma and Immunology (AAAAI) Annual Meeting: Atlanta, GA; 3-6 March 2017.

33. Shida Y, Takahashi N, Sakamoto T, Ino H, Endo A, Hirama T. The pharmacokinetics and safety profiles of belimumab after single subcutaneous and intravenous doses in healthy Japanese volunteers. J Clin Pharm Ther. 2014;39(1):97-101. https://doi.org/10. $1111 /$ jept.12101.

34. Carpenter TO, Imel EA, Ruppe MD, Weber TJ, Klausner MA, Wooddell MM, et al. Randomized trial of the anti-FGF23 antibody KRN23 in X-linked hypophosphatemia. J Clin Investig. 2014;124(4):1587-97. https://doi.org/10.1172/JCI72829. 
35. Chakraborty A, Tannenbaum S, Rordorf C, Lowe PJ, Floch D, Gram H, et al. Pharmacokinetic and pharmacodynamic properties of canakinumab, a human anti-interleukin-1beta monoclonal antibody. Clin Pharmacokinet. 2012;51(6):e1-18. https://doi.org/ 10.2165/11599820-000000000-00000.

36. van Hartingsveldt B, Nnane IP, Bouman-Thio E, Loza MJ, Piantone A, Davis HM, et al. Safety, tolerability and pharmacokinetics of a human anti-interleukin-13 monoclonal antibody (CNTO 5825) in an ascending single-dose first-in-human study. Br J Clin Pharmacol. 2013;75(5):1289-98. https://doi.org/10.1111/j.13652125.2012.04477.x.

37. Baker B, Hodsman P, Smith J. PK \& PD supporting a single dose, placebo-controlled randomized ascending dose study of ALD403, a humanized anti-calcitonin gene-related peptide (CGRP) monoclonal antibody administered IV or SC. 17th Congress of the International Headache Society; Valencia: 14-17 May 2015.

38. Xu Z, Wang Q, Zhuang Y, Frederick B, Yan H, Bouman-Thio E, et al. Subcutaneous bioavailability of golimumab at 3 different injection sites in healthy subjects. J Clin Pharmacol. 2010;50(3):276-84. https://doi.org/10.1177/0091270009340782.

39. White B, Leon F, White W, Robbie G. Two first-in-human, openlabel, phase I dose-escalation safety trials of MEDI-528, a monoclonal antibody against interleukin- 9 , in healthy adult volunteers. Clin Ther. 2009;31(4):728-40. https://doi.org/10.1016/j.clinthera. 2009.04.019.

40. Smith DA, Minthorn EA, Beerahee M. Pharmacokinetics and pharmacodynamics of mepolizumab, an anti-interleukin-5 monoclonal antibody. Clin Pharmacokinet. 2011;50(4):215-27. https:// doi.org/10.2165/11584340-000000000-00000.

41. Ignatenko S, Skrumsager BK, Mouritzen U. Safety, PK, and PD of recombinant anti-interleukin-21 monoclonal antibody in a firstin-human trial. Int J Clin Pharmacol Ther. 2016;54(4):243-52. https://doi.org/10.5414/CP202474.

42. Khatri A, Eckert D, Oberoi R, Suleiman A, Pang Y, Cheng L, et al. Pharmacokinetics of risankizumab in asian healthy subjects and patients with moderate to severe plaque psoriasis, generalized pustular psoriasis, and erythrodermic psoriasis. J Clin Pharmacol. 2019;59(12):1656-68. https://doi.org/10.1002/jcph.1473.

43. Pharmaceutical and Medical Devices Agency (PMDA). Secukinumab (Cosentyx). 2014. https://www.pmda.go.jp/drugs/2014/ P201400171/index.html. Accessed 1 Mar 2020.

44. Zhuang Y, de Vries DE, Marciniak SJ, Liu H, Zhou H, Davis $\mathrm{HM}$, et al. Absolute bioavailability and pharmacokinetic comparability of sirukumab following subcutaneous administration by a prefilled syringe or an autoinjector. Clin Pharmacol Drug Dev. 2017;6(6):570-6. https://doi.org/10.1002/cpdd.328.

45. Khalilieh S, Hodsman P, Xu C, Tzontcheva A, Glasgow S, Montgomery D. Pharmacokinetics of Tildrakizumab (MK-3222), an anti-IL-23 monoclonal antibody, after intravenous or subcutaneous administration in healthy Subjects. Basic Clin Pharmacol Toxicol. 2018;123(3):294-300. https://doi.org/10.1111/bcpt.13001.
46. Gow JM, Tsuji WH, Williams GJ, Mytych D, Sciberras D, Searle SL, et al. Safety, tolerability, pharmacokinetics, and efficacy of AMG 403, a human anti-nerve growth factor monoclonal antibody, in two phase I studies with healthy volunteers and knee osteoarthritis subjects. Arthritis Res Ther. 2015;17:282. https:// doi.org/10.1186/s13075-015-0797-9.

47. Cavelti-Weder C, Babians-Brunner A, Keller C, Stahel MA, KurzLevin M, Zayed H, et al. Effects of gevokizumab on glycemia and inflammatory markers in type 2 diabetes. Diabetes Care. 2012;35(8):1654-62. https://doi.org/10.2337/dc11-2219.

48. Levisetti M, Joh T, Wan H, Liang H, Forgues P, Gumbiner B, et al. A phase I randomized study of a specifically engineered, pH-sensitive PCSK9 Inhibitor RN317 (PF-05335810) in hypercholesterolemic subjects on statin therapy. Clin Transl Sci. 2017;10(1):3-11. https://doi.org/10.1111/cts.12430.

49. Parnes JR, Sullivan JT, Chen L, Dias C. Pharmacokinetics, safety, and tolerability of tezepelumab (AMG 157) in healthy and atopic dermatitis adult subjects. Clin Pharmacol Ther. 2019;106(2):4419. https://doi.org/10.1002/cpt.1401.

50. Khanskaya I, Pinkstaff J, Marino HM, Savall T, Li J, Londei M. A Phase 1 Study of ANB019, an Anti-Interleukin-36-Receptor (IL-36R) Monoclonal Antibody, in Healthy Volunteers. European Academy of Allergy and Clinical Immunology (EAACI) Congress; Munich: 26-30 May 2018.

51. Staton TL, Peng K, Owen R, Choy DF, Cabanski CR, Fong A, et al. A phase I, randomized, observer-blinded, single and multiple ascending-dose study to investigate the safety, pharmacokinetics, and immunogenicity of BITS7201A, a bispecific antibody targeting IL-13 and IL-17, in healthy volunteers. BMC Pulm Med. 2019;19(1):5. https://doi.org/10.1186/s12890-018-0763-9.

52. Kotani N, Yoneyama K, Kawakami N, Shimuta T, Fukase H, Kawanishi T. Relative and absolute bioavailability study of emicizumab to bridge drug products and subcutaneous injection sites in healthy volunteers. Clin Pharmacol Drug Dev. 2019;8(6):702-12. https://doi.org/10.1002/cpdd.617.

53. Oh CK, Faggioni R, Jin F, Roskos LK, Wang B, Birrell C, et al. An open-label, single-dose bioavailability study of the pharmacokinetics of CAT-354 after subcutaneous and intravenous administration in healthy males. Br J Clin Pharmacol. 2010;69(6):64555. https://doi.org/10.1111/j.1365-2125.2010.03647.x.

54. Kretsos K, Golor G, Jullion A, Hickling M, McCabe S, Shaw $\mathrm{S}$, et al. Safety and pharmacokinetics of olokizumab, an antiIL-6 monoclonal antibody, administered to healthy male volunteers: a randomized phase I study. Clin Pharmacol Drug Dev. 2014;3(5):388-95. https://doi.org/10.1002/cpdd.121. 